\title{
Perceived Barriers to Integrating Social Science and Conservation
}

\author{
HELEN E. FOX, ${ }^{*} \neq \ddagger$ CAROLINE CHRISTIAN, $†$ J. CULLY NORDBY,$\ddagger$ OLIVER R. W. PERGAMS,$\S$ \\ GARRY D. PETERSON,$^{* *}$ AND CHRISTOPHER R. PYKE $\dagger \dagger$ \\ ${ }^{*}$ Hawaii Institute of Marine Biology, PO Box 1346, Kaneohe, HI 96744, U.S.A. \\ †Department of Environmental Studies and Planning, Sonoma State University, Rohnert Park, CA 94928, U.S.A. \\ ‡Department of Ecology and Evolutionary Biology and Institute of the Environment, University of California, 621 Charles E. Young \\ Dr. South, Los Angeles, CA 90095, U.S.A. \\ $\S$ Department of Biological Sciences, University of Illinois at Chicago, 845 W. Taylor Street, Chicago, IL 60607-7060, U.S.A. \\ ${ }^{* *}$ Department of Geography \& McGill School of the Environment, McGill University, 805 Sherbrooke Street W., Montreal, Quebec \\ H3A 2K6, Canada \\ ††National Center for Ecological Analysis and Synthesis, University of California, Santa Barbara, 735 State Street, Suite 300, Santa \\ Barbara, CA 93101-3351, U.S.A.
}

\section{The Limitations of Conservation Biology}

The ecology of threatened species and ecosystems is the foundation of conservation biology, but ecological knowledge is not sufficient for conservation success. Conservation actions are ultimately human behaviors, and it is vital to understand how social factors (e.g., markets, cultural beliefs and values, laws and policies, demographic change) shape human interactions with the environment and choices to exploit or conserve biodiversity (Mascia et al. 2003). Many conservationists recognize the importance of the social dimensions of conservation problems, but anecdotal observations suggest that conservation biologists perceive a gap between the biological and social sciences that limits the effectiveness of conservation action. Casual conversations among biologists frequently include phrases such as: "I am not an economist, but...," "We understand the biology, but the political process remains our biggest challenge," or "We cannot convey the uncertainty in our findings to decision makers."

Acknowledgment of the existence of a gap between natural and social sciences is nothing new (Nyhus et al. 2002; Cheng et al. 2003); however, the recognition and sense of urgency to bridge this gap seems to be growing among biologists, policy makers, and funders (Baxter et al. 1999). Opportunities to integrate social science techniques into conservation practice have been promoted by nongovernmental organizations (e.g., Chornesky et al. 2001; Community Conservation Coalition 2003), government agencies (Machlis 1996), and academia (Noss 1997). Recent editorials in Conservation Biology (e.g., Mascia et al. 2003) and the formation of a Social Sciences Working Group by the Society for Conservation Biology (Thornhill 2003) suggest that progress is being made. These contributions define the needs and demonstrate tools and strategies, but it is also apparent that the goal of a truly interdisciplinary approach to biodiversity conservation has not been realized (Rosa \& Machlis 2002; Fazey et al. 2005). We believe there is a lack of information about perceived barriers to effective collaboration between social scientists and conservation biologists. The reasons for the gaps between these disciplines should be carefully considered so that remedial action based on empirical data can be put into effect. In other words, yet again, an adaptive management approach to problem solving is needed. Relevant data will be gained by studying the population of scientists most relevant to bridging this gap: natural and social scientists interested in biological conservation.

\section{Surveying the Fields}

The scale and scope of this problem suggests that a substantial effort is needed to identify the most important

¥Current address: Conservation Science Program, World Wildlife Fund-U.S., 1250 24th Street NW, Washington, D.C. 20037, U.S.A., email helen.fox@wwfus.org

Paper submitted July 21, 2005; revised manuscript accepted August 29, 2006. 
real and perceived barriers to collaboration and integrating social science into conservation action. We conducted a modest pilot study to develop preliminary data, in the hopes that our initial results would be sufficiently interesting to motivate more extensive (and expensive) work. We used a simple on line survey to assess world views, perspectives about the role of social science in conservation, and, most importantly, perceived barriers to collaboration. We solicited participation from groups likely to have a vested interest and informed opinion about these issues, targeting 13 email list servers reaching audiences of biological and social scientists broadly associated with conservation issues.

We received responses from a diverse group of 360 individuals, 311 of whom lived in the United States. Education level was self-reported by 168 of the respondents, most of whom had a doctoral (42\%) or master's degree (40\%); the remainder had a bachelor's degree (17\%). The median degree date was 1997 , but the distribution ranged from 1956 to 2003 and was highly skewed toward more recent degrees. The majority of the respondents were employed in academia (52\%); however, those working for nongovernmental organizations $(23 \%)$ or governments (15\%) were also well represented. The majority of individuals described themselves as natural scientists (61\%). Twenty-one percent were social scientists, and 15\% were nonscientists, although we received a higher estimated response rate from social scientists (approximately 12\%) than natural scientists (approximately 1.6\%). Our estimates were based on approximate numbers of list server subscribers as provided by listserv managers. These low response rates mean we cannot draw broad conclusions about the views of the groups as a whole because we know little about the differences between our respondents and those who did not choose to take the survey. Nevertheless, our goal was to explore attitudes rather than fully characterize them, and our respondents represented a self-identified group of people interested in the role of social science in conservation.

In setting up our survey we wondered whether natural and social scientists have incompatible views on the fundamental goals and objectives of conservation. Respondents held a diversity of environmental views, which appeared to be relatively evenly distributed across educational, professional, or scientific divisions. Overall, views within practitioners of the two disciplines seem unlikely to pose a problem to cross-disciplinary collaboration.

Alternatively, it is possible that individuals differed in their perceptions of the importance or prevalence of social science in current conservation science, which could create a barrier to collaboration. Our sample strongly agreed that social sciences are important and can contribute to conservation success. Nevertheless, perceptions of prevalence varied. All respondents, but especially social scientists, tended to agree that conservation activities are dominated by biological analysis (Fig. 1a), but not

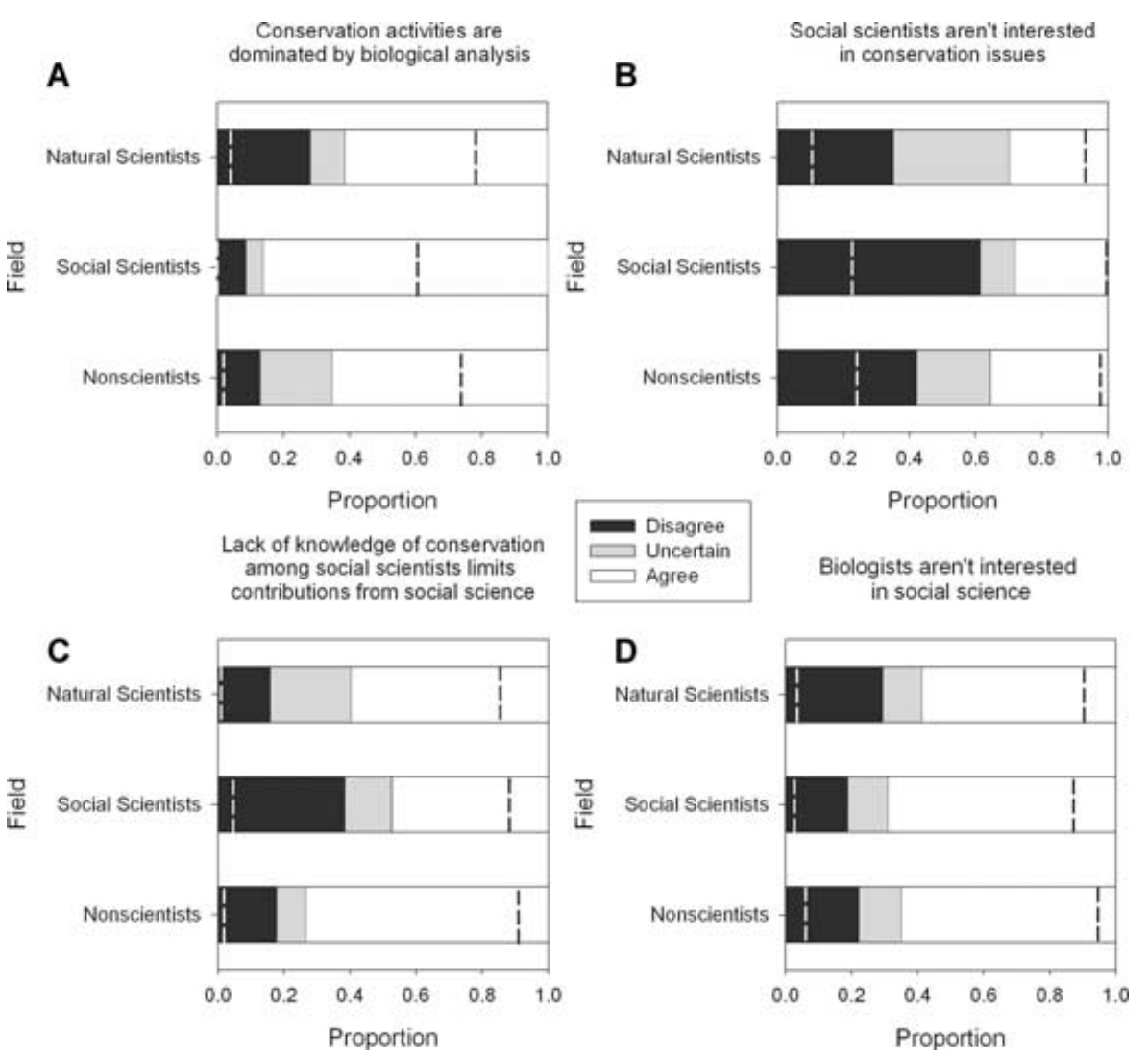

Figure 1. Responses to questions about barriers to collaboration between natural and social scientists (A-D, above plots) that bigblight similar or different perceptions among natural, social, and nonscientists. Dotted lines divide Likert categories 1 and 2 (strongly disagree and disagree, respectively) and 4 and 5 (agree and strongly agree, respectively). 
for lack of interest among social scientists (Fig. 1b). We therefore inferred that the social scientists in our group saw the gap and were interested in closing it. In other words if social scientists are perceived to be interested in conservation issues, why are they perceived to be less engaged in these issues? Nearly half of social scientists and even more natural scientists agreed that a lack of knowledge of conservation (i.e., formal education or familiarity with the facts and theories in the field) among social scientists limited the field's contributions (Fig. 1c); however, the majority of respondents believed biologists are not interested in social science (Fig. 1d). Despite a belief that social science is an important part of conservation action, on average our sample tended to think that biologists might not recognize or value the contributions of a good social scientist.

We also gave respondents the chance to frame the issue in their own words. In many cases their observations conveyed more useful and nuanced information than our statistics. Some respondents believed there were severe problems with natural or social science that needed to be addressed before meaningful collaboration could take place. One respondent wrote, "... no matter how much good science exists to support an argument, economics (greed) and power drive policy and squash conservation efforts. Scientists need to take a stand more often on issues, become more politically active, and become more involved in the education of the average people who currently view conservation biologists as alarmist geeky snobs who care more about animals than people" (natural scientist with a master's degree).

More encouraging, however, were comments that clearly reflected the value respondents put on interdisciplinary collaboration and the strong feeling that social science can improve conservation action. "I definitely feel limited by my ecology-oriented training, as I am now faced [with] working with species whose threats largely involve direct exploitation by economically struggling local people, and feel that I could learn a lot from educators and social scientists. However, I also find myself frustrated at times with the social science literature" (natural scientist with a doctoral degree).

\section{Barriers and Recommendations}

Although a number of interdisciplinary studies have addressed human behavior and its effect on biodiversity or habitat (e.g., Forester \& Machlis 1996; Czech \& Krausman 1997; Johnson \& Graber 2002; Brook et al. 2003), these tend to be the exception rather than the rule. Thus, there is clearly room for improvement. Our respondents perceived the strongest barriers to integration of the social sciences as (1) the lack of common vocabulary between biologists and social scientists, (2) the fact that traditional academic reward systems discourage interdisciplinary collaboration and applied problem solving, (3) the lack of funding for collaborative work, and (4) limited opportunities for interdisciplinary collaboration. These observations closely follow widely recognized barriers to interdisciplinary research in general (Metzger \& Zare 1999).

Another problem identified is that natural scientists often only involve social scientists at the end of a project, which makes the research less interesting to the social scientist and so inhibits collaboration. One respondent commented: "In my experience, natural scientists turn to social scientists to better package or market their eco/bio principles to the general public. True collaboration suggests mutual recognition of the distinct theory and method that respective disciplines can bring to complex problems" (social scientist with a doctoral degree).

Addressing these complex problems often requires interdisciplinary effort and writing projects with many authors, yet the emphasis academia places on singleauthored papers can serve as an additional barrier (Gober 2000). Furthermore, although it is the applied tools from both social science and conservation biology that are most needed for successful conservation implementation, it is the theoretical branches of both disciplines that are more cutting edge and merit publications in the prestigious peer-reviewed journals of the field. A related concern is that focusing on applied issues may lead to a decrease in scientific rigor (Lidicker 1998): “... missing $\ldots$ is the importance of conservation biologists in being rigorous scientists. I think bringing human dimensions to the biology is already happening, but often at the expense of 'good science"' (natural scientist with doctoral degree).

Although it is important to maintain scientific integrity, these attitudes can hinder effective conservation action. Others argue that applied work often leads to scientific innovation (Holling 1978; Walters 1986; Hilborn \& Mangel 1997), and new fields such as conservation biology and ecosystem ecology have emerged from practical questions of biodiversity loss, acid rain, and other conservation issues.

Several recommendations for breaking down the barriers and improving the effectiveness of conservation action through the integration of social science emerged: "... I believe a key impediment to integrating across the social sciences is often a simple lack of mutual respect. Many academics are taught an egotism that is very difficult to manage when interdisciplinary projects are attempted. Both social and natural scientists need to assume, from the start, that their colleagues 'on the other side' have approaches that are worth considering" (social scientist with a doctoral degree).

Ways to encourage respect for others' approaches include increased support (funding and graduate training, e.g., Kainer et al. 2006) for interdisciplinary work (also 
suggested by other authors, e.g., Noss 1997; Meffe et al. 1998; Mascia et al. 2003) and the Society for Conservation Biology's formation of the Social Sciences Working Group. Academic dialog on these subjects extends far beyond the discussion here, and there is a significant body of social science research about issues in interdisciplinary science. Nevertheless, most of these studies are within the social sciences literature and are thus unlikely to be widely read by conservation biologists (e.g., Jakobsen et al. 2004). Publications such as Journal of Environmental Management, Natural Resources Journal, and Society and Natural Resources are oriented toward interdisciplinary communication in natural resource management but are rarely cited in papers in Conservation Biology. Our experience with this survey has been, in part, a microcosm of the problem we were trying to examine. We discovered that we would have benefited greatly from early collaboration with social scientists experienced with survey design.

Nonetheless, we found that natural and social scientists shared broadly similar views about conservation problems. They recognized common barriers to collaboration. Many of these problems are familiar, such as the lack of a common language or the lack of funding for interdisciplinary research. Perhaps more interesting is the observation that social scientists do not perceive conservation biologists as particularly receptive to their help. Bridging this gap is not necessarily a matter of money. Rather, it is a question of attitude. Both sides agree that better collaboration would contribute to conservation success. We hope that as the biodiversity crisis continues conservation biologists and social scientists can make collaboration happen.

\section{Acknowledgments}

This work was supported by The Nature Conservancy's David H. Smith Conservation Research Fellowship Program. We thank J. C. Haney for the initial impetus to conduct this survey, L. Shipley for Web site design, and J. C. Haney, M. Mascia, R. Robison, and several anonymous reviewers for their helpful comments on the manuscript. This is publication DHS2006-05 of the David H. Smith Conservation Research Fellowship Program.

\section{Literature Cited}

Baxter, G. S., M. Hockings, R. W. Carter, and R. J. S. Beeton. 1999. Trends in wildlife management and the appropriateness of Australian university training. Conservation Biology 13:842-849.
Brook, A., M. Zint, and R. De Young. 2003. Landowners' responses to an endangered species act listing and implications for encouraging conservation. Conservation Biology 17:1638-1649.

Cheng, A. S., L. E. Kruger, and S. E. Daniels. 2003. "Place" as an integrating concept in natural resource politics: propositions for a social science research agenda. Society and Natural Resources 16:87-104.

Chornesky, E., D. Forester, E. Hamilton, and P. Szabo. 2001. People matters: The Nature Conservancy's use of social science tools to understand and work within the human context of conservation. The Nature Conservancy, Washington, D.C.

Community Conservation Coalition. 2003. Putting conservation in context: social science tools for conservation practitioners CD-ROM. Community Conservation Coalition, Washington, D.C.

Czech, B., and P. R. Krausman. 1997. Distribution and causation of species endangerment in the United States. Science 277:1116-1117.

Fazey, I., J. Fischer, and D. B. Lindenmayer. 2005. What do conservation biologists publish? Biological Conservation 124:63-73.

Forester, D. J., and G. E. Machlis. 1996. Modeling human factors that affect the loss of biodiversity. Conservation Biology 10:1253-1263.

Gober, P. 2000. In search of synthesis. Annals of the Association of American Geographers 90:1-11.

Hilborn, R., and M. Mangel. 1997. The ecological detective: confronting models with data. Princeton University Press, Princeton, New Jersey.

Holling, C. S., editor. 1978. Adaptive environmental assessment and management. John Wiley and Sons, London.

Jakobsen, C. H., T. Hels, and W. J. McLaughlin. 2004. Barriers and facilitators to integration among scientists in transdisciplinary landscape analyses: a cross-country comparison. Forest Policy and Economics 6:15-31.

Johnson, S. E., and B. E. Graber. 2002. Enlisting the social sciences in decisions about dam removal. Bioscience 52:731-738.

Kainer, K. A., M. Schmink, H. Covert, J. R. Stepp, E. M. Bruna, J. L. Dain, S. Espinosa, and S. Humphries. 2006. A graduate education framework for tropical conservation and development. Conservation Biology 20:3-13.

Lidicker, W. 1998. Revisiting the human dimension in conservation biology. Conservation Biology 12:1170-1171.

Machlis, G. E. 1996. Usable knowledge: a plan for furthering social science and the national parks (summary). National Park Service, Washington, D.C.

Mascia, M. B., J. P. Brosius, T. A. Dobson, B. C. Forbes, L. Horowitz, M. A. McKean, and N. J. Turner. 2003. Conservation and the social sciences. Conservation Biology 17:649-650.

Meffe, G. K., R. F. Noss, and S. K. Jacobson. 1998. Revisiting the human dimension in conservation biology. Conservation Biology 12:11711172 .

Metzger, N., and R. N. Zare. 1999. Interdisciplinary research: from belief to reality. Science 283:642-643.

Noss, R. F. 1997. The failure of universities to produce conservation biologists. Conservation Biology 11:1267-1269.

Nyhus, P. J., F. R. Westley, R. C. Lacy, and P. S. Miller. 2002. A role for natural resource social science in biodiversity risk assessment. Society and Natural Resources 15:923-932.

Rosa, E. A., and G. E. Machlis. 2002. It's a bad thing to make one thing into two: disciplinary distinctions as trained incapacities. Society and Natural Resources 15:251-261.

Thornhill, A. 2003. Social scientists and conservation biologists join forces. Conservation Biology 17:1476.

Walters, C. J. 1986. Adaptive management of renewable resources. McGraw Hill, New York. 